\title{
Regulatory challenges relating to tissue banks in South Africa: Impediments to accessing healthcare
}

\author{
M Labuschaigne, BA, BA(Hons), MA, DLitt, LLB, LLD; S Mahomed, BCom, LLB, LLM, PhD \\ Department of Jurisprudence, School of Law, College of Law, University of South Africa, Pretoria, South Africa
}

Corresponding author: M Labuschaigne (Slabbmn@unisa.ac.za)

The demand for human tissue in the medical context has increased rapidly since the early 1980s, when the use of human bone in allografts in orthopaedic surgery became the norm. During the 1990s, the demand for human tissue turned towards tissue-engineered products in the field of regenerative medicine. Tissue engineering, as an established and growing interdisciplinary field comprising different specialties, such as medicine, materials science, cell biology, genomics and chemical engineering, aims to develop biological substitutes to restore, maintain or improve tissue function, thus offering patients the chance to regain normal functionality in their bodies. The purpose of this article is to explore some of the gaps that exist in the current regulatory framework that governs tissue banks in South Africa (SA), and to make certain recommendations aimed at closing these gaps. The discrepancies and gaps cause confusion and may lead to undesired and unforeseen consequences regarding the use of human tissue, as well as prejudice the welfare of patients in SA.

S Afr J Bioethics Law 2019;12(1):27-31. DOI: 10.7196/SAJBL.2019.v12i1.674

The demand for human tissue in the medical context has increased rapidly since the early 1980s, when human bone, used in allografts in orthopaedic surgery, became the norm. During the 1990s, the demand for human tissue turned towards tissue-engineered products in the field of regenerative medicine.

Tissue engineering, as an established and growing interdisciplinary field comprising different specialties, such as medicine, materials science, cell biology, genomics and chemical engineering, aims to develop biological substitutes to restore, maintain or improve tissue function, thus offering patients the chance to regain normal functionality in their body. ${ }^{[1]}$

Tissue allografts, in other words, tissue transplanted from one person to another, are used to save and improve the lives of millions of people each year. For example, such allografts may refer to:

- donated heart valves to replace damaged valves, or correct congenital defects, allowing the heart to function normally

- musculoskeletal tissue to save limbs from amputation and to replace bone, tendons and ligaments lost to cancer, severe trauma, degenerative joint disease, arthritis or other conditions

- donated skin to save the lives of burn victims and improve the lives of patients with significant soft-tissue defects.

Tissue-engineered products include, among others, tissueengineered bone products (used in periodontal and jawbone surgery, and to treat certain bone fractures, osteoporosis and bone tumours), tissue-engineered skin products (to treat, for example, burns, chronic wounds and other major traumas to the skin, including the treatment and prevention of scarring and pigmentation disorders), tissue-engineered cartilage products (to treat, for example, cartilage defects in the knee and other joints due to traumatic injury) and tissue-engineered cardiovascular products (used primarily in the treatment of cardiovascular diseases, e.g. biological heart valves, vessel grafts and cell grafting into the heart muscle, e.g. after myocardial infarction). In addition to medical applications, tissue-engineered products may be used in non-therapeutic applications such as the use of tissue to create biosensors, which aim to detect biological or chemical threat agents, and tissue chips that can be used to test the toxicity of an experimental medication. ${ }^{[2]}$

Tissue-engineered products may further be distinguished in terms of their type, into the following product categories:

- autologous products, derived from cells and tissues removed from one person and used in/on the same person, normally associated with less frequent adverse immune complications

- allogeneic products, derived from cells or tissues removed from one person and used in/on another person, normally associated with a higher potential for adverse immune complications

- xenogeneic products, derived from cells or tissues removed from an organism of another species and used in/on a human patient these products, however, reveal high immunogeneic potential, including a high risk of transmission of viral infections. ${ }^{[3]}$

The legal framework for the regulation of tissue in South Africa (SA) consists primarily of chapter 8 of the National Health Act (NHA) No. 61 of $2003,{ }^{[4]}$ and regulations governing the use and control of blood, blood products, tissue and gametes. Regulations relevant to tissue and tissue banks are the regulations relating to: the general control of human bodies, tissue, blood, blood products and gametes; ${ }^{[5]}$ the use of human biological material, ${ }^{[6]}$ the import and export of human tissue, blood, blood products, cultured cells, stem cells, embryos, fetal tissue, zygotes and gametes; ${ }_{i}^{[7]}$ stem cell banks; ${ }^{[8]}$ the artificial fertilisation of persons; ${ }^{[9]}$ and, most importantly, tissue banks. ${ }^{[10]}$ These together provide the legal framework for the regulation, and the use, of human tissue. 
The purpose of this article is to explore some of the gaps that exist in the current regulatory framework governing tissue banks in SA, and to make certain recommendations aimed at closing these gaps. The discrepancies and gaps identified below cause confusion and may lead to undesired and unforeseen consequences regarding the use of human tissue, as well as prejudice the welfare of patients in SA.

\section{Lack of clarity on the scope and definition of human tissue-related terminology Tissue}

The NHA defines tissue in section 1 as 'human tissue, and includes flesh, bone, a gland, an organ, skin, bone marrow or body fluid, but excludes blood or a gamete. ${ }^{[4]}$ The regulations relating to tissue banks, on the other hand, define tissue as 'a functional group of cells', and as a term that 'is used collectively in regulations to indicate both cells and tissue. ${ }^{[10]}$ As this definition refers to cells, clarity on the definition of cells is necessary.

\section{Cell}

Unfortunately, one again finds multiple definitions of a cell in the $\mathrm{NHA}$ and the regulations. The regulations relating to the artificial fertilisation of persons describe a cell as 'the basic structural and functional unit in people and all living things ${ }^{\prime[9]}$ in contrast to the definition found in the regulations relating to the use of human biological material, which define a cell as 'the smallest structural and functional unit of an organism, consisting of cytoplasm and a nucleus enclosed in a membrane in living things! ${ }^{\prime[6]}$

\section{Cultured cells}

Similar discrepancies appear in the definitions of cultured cells in the regulations relating to the use of human biological material, which define these as 'cells that have been grown outside the body, ${ }_{1}^{[6]}$ and the definition in the regulations relating to the import and export of human tissue, blood, blood products, cultured cells, stem cells, embryos, fetal tissue, zygotes and gametes, which describe these cells as 'any human cells grown in vitro supported by suitable growth media.[7] Although clinicians and researchers may generally not view these definitions as overly conflicting, these differing descriptions display careless legal drafting, which is compounded by regulatory gaps that exist when all the relevant regulations promulgated in terms of chapter 8 of the NHA are read together when clarity is sought on ambiguities or lacunae.

\section{Human biological material}

Although the NHA itself does not refer to 'human biological material' (despite the existence of an entire set of regulations promulgated in terms of chapter 8 of the Act), the term appears to refer to a comprehensive understanding of human biological material, and is defined in the regulations relating to human biological material to include 'DNA, RNA, blastomeres, polar bodies, cultured cells, embryos, gametes, progenitor stem cells, small tissue biopsies and growth factors from the same. ${ }^{[6]}$ Despite the variation in the descriptions of the same term in some of the regulations relating to different contexts (such as 'cells' and 'cultured cells'), better-aligned and more consistently worded definitions are required in all of the regulations. If not, a clear and unambiguous interpretation of chapter 8 regulations relating to human tissue will remain a challenge.

\section{Tissue bank}

The regulations relating to tissue banks define a tissue bank as 'an organisation, institution or person that provides or engages in one or more services involving cells and/or tissue from living or deceased individuals for transplantation purposes, and is registered in terms of regulation 3 of these regulations' ${ }^{\prime[10]}$ (regulation 3 describes the requirements for the application process for a tissue bank, to the Department of Health (DoH)). The reference to a 'person' as a tissue bank in the definition of a tissue bank, assuming this is meant to refer to a natural person and not a juristic person, is odd if one considers that the rest of the requirements relevant to the establishment and authorisation of a human tissue bank require the involvement of multiple role-players.

\section{Tissue dispensing service}

The regulations relating to tissue banks also refer to another entity, described as a tissue dispensing service, defined as 'any entity that receives, stores and provides cells and/or tissue directly to an enduser for immediate transplantation. Tissue dispensing services may or may not be tissue banks, depending on what other functions they perform' ${ }^{\prime 10]}$ (emphasis added). The same regulations mention another entity, namely a dispensing service, which, on the other hand, is defined as a 'facility responsible for the receipt, maintenance and delivery to the ultimate user (e.g. transplanting surgeon, surgical centre or research facility) of cells and/or tissue for transplantation or research' ${ }^{[10]}$ (emphasis added). This is curious, considering that all further references in the regulations are to 'tissue dispensing services' and nowhere else are 'dispensing services' mentioned. The only conclusion to be drawn from these different entities is that a 'dispensing service' may receive, store/maintain and deliver/provide cells and/or tissue to research facilities and end-users for research and transplantation purposes, whereas a 'tissue dispensing service' may only store/maintain and deliver/provide cells and/or tissue directly for immediate transplantation to an end-user, and not to a research facility for research purposes.

Moreover, the definition of tissue bank refers to a tissue bank providing or engaging in 'one or more services involving cells and/ or tissue [...] for transplantation purposes' ${ }^{\prime 10]}$ (emphasis added), and does not mention research using the cells or tissues. Regulation 17 of the same tissue bank regulations refers to the requirements pertaining to activities at tissue banks which include'the research and development of tissue samples.[10] It is submitted that this ambiguity in the regulations, which on the one hand relate the purpose of a tissue bank to transplantation as per the definition in the regulation, yet on the other mention research as one of a tissue bank's activities, compounded by the lack of clarity between a 'tissue bank', a 'tissue dispensing service' and a 'dispensing service', and also considering that there are no regulations governing biobanks specifically in SA, has led to confusion regarding the role and functions of tissue banks and biobanks in SA, respectively. The discussion on biobanks below will provide more context to the legal uncertainty that has resulted in this regard.

\section{Biobank}

The use of biobanks, which store and distribute human biological materials (including human tissues) and associated data for the purposes of health research, has increased dramatically, as indicated 
by the growth in their numbers and size. ${ }^{[1]}$ Significantly, biobanks, which involve the extensive networking of human tissue and associated data, are not legally regulated in SA. However, they are regulated in a limited and fragmented way by the DoH's ethics guidelines. ${ }^{[12]}$ A national Material Transfer Agreement (MTA) of human biological materials, which partially regulates biobank research, was gazetted as a framework for compulsory use in July 2018. ${ }^{[13]}$ Biobanks are generally confused with tissue banks, and since the regulations promulgated in terms of chapter 8 of the NHA make no reference to biobanks, researchers and clinicians turn to the tissue bank regulations for direction and guidance, even though they are clearly inadequate. It has been argued ${ }^{[14]}$ that the definition of a tissue bank in the regulations referred to above is very limited, and incompatible with the definition of a biobank.

The purpose of a biobank is to promote research that generates new science, with the intention of benefiting human wellbeing and health, to make data and materials accessible to researchers in order to advance knowledge and understanding, and to ensure the integrity of samples in perpetuity. ${ }^{[15]}$ The second (2015) edition of the DoH's Ethics in Health Research: Principles, Processes and Structures ${ }^{[12]}$ refers to biobanks and 'repositories' interchangeably, and defines the concept as:

'a collection, storage and distribution system for human biological materials for research purposes, including blood, urine, faeces, bone marrow, cell aspirates, diagnostic specimens, pathology specimens and so on. Usually demographic and medical information about the donors is included in the repository, as are codes that link the material to the donors.

The recently gazetted national MTA template ${ }^{[13]}$ defines a biobank as: 'an institution or unit thereof that safeguards an organised collection of human biological materials and associated data from different individuals, which are usually kept for an unlimited period of time, for the purposes of health research.

\section{Tissue bank v. biobank}

The clearest difference between a tissue bank and a biobank relates to the purpose for the existence of each - a tissue bank provides services relating to cells and tissue from dead or living donors for transplantation purposes, whereas in the case of a biobank, the ultimate purpose is research.

Biobanking started with small, mainly university-based repositories that were developed for specific research projects, but these have lately evolved into complex institutional and government repositories, including commercial biorepositories and population-based biobanks, some of which may contain extensive information sets encompassing many aspects of participant or patient phenotype. ${ }^{[16]}$

The types of tissue establishments or facilities that currently exist in SA are equally varied. Tissue establishment in this sense is a broad term that includes tissue laboratories and tissue banks generally. SA has one leading authorised multi-tissue bank, namely the Centre for Tissue Engineering (CTE), which forms part of the Department of Biomedical Sciences and operates under the Faculty of Science at the Tshwane University of Technology. The CTE procures and processes donor tissue for therapeutic purposes. The CTE has an agreement with Bone SA, a non-profit company, regarded as SA's main tissue dispensing facility. Other tissue establishments are the
Eyebank Foundation SA, the Gauteng Cornea and Eye Bank, the Homograft Bank, Next Biosciences, the Tissue Lab at the University of the Free State and CryoSave SA Family Stem Cell Bank, to mention but a few.

\section{Regulatory gaps}

The deficiencies with regard to the regulation of cells and tissues, some of which are referred to above, have been reported by scholars for almost a decade. They include, among others, the lack of regulations addressing cell-based therapy, biobanks and tissue transplantation, complicated by ambiguous and conflicting provisions and definitions contained in the regulations and the $\mathrm{NHA} .{ }^{[17]}$

Because of these legislative gaps, some practitioners and researchers have developed their own regulatory guidelines in an attempt to self-regulate. One such association that was established is the SA Tissue Bank Association (SATiBA), a non-profit organisation that aims to support all SA tissue banks in regulatory and legal matters, data collection, training, accreditation, quality assurance and collaboration, with the assistance of a code of conduct for members. ${ }^{[18]}$

SA unfortunately does not have a national tissue procurement agency, or alternatively, a national tissue authority, similar to the UK's Human Tissue Authority (HTA). The HTA, created by the Human Tissue Act of 2004, is an executive non-departmental public body of the UK Department of Health, regulating the removal, storage, use and disposal of human bodies, organs and tissue, for a number of scheduled purposes such as research, transplantation and education and training. Such an authority in SA would strengthen the regulatory framework relating to the procurement and supply of human tissue, and be better equipped to address challenges arising in the rapidly developing field of human tissue research and applications, as is the case in the UK.

In the following section, we discuss a further complication, namely the lack of supply of tissue nationally, exacerbated by the current position where one main multi-tissue bank serves the entire country. The diversity of tissue banks, not to mention confusion regarding which types of banking activities constitute research-related activities or human subject research pertaining to biobanks and tissue banks, further obscures the current situation, as the discussion on the difference between biobanks and tissue banks below will illustrate.

\section{Human tissue supply}

A recent research report by Hexa Research ${ }^{[19]}$ estimated the value of the global tissue-engineering market in 2015 to have been around USD23.3 billion, anticipating that it would exceed USD 94.7 billion at a growing compound annual growth rate of $23 \%$ in the next few years. This growth will be fuelled by the influence of increasing chronic diseases, increasing longevity, government initiatives and improvement of healthcare facilities on the growth of the tissuebanking market. In addition, new advanced techniques for tissue banking will also impact on the tissue-banking market in the near future.

In the Middle East and Africa region, Egypt and Saudi Arabia are the largest tissue-engineering markets, with SA emerging as the most significant player in the southern African market. With an everincreasing demand for tissue, the absence of a national tissue bank has become a concern. 


\section{Risks to the supply of human tissue}

A recent Bone SA feasibility study (unpublished internal report), carried out in March 2018, on de-risking the security of the supply of bone, identifies a number of critical risks that explain the current wholly inadequate supply of tissue to Bone SA for national distribution. The effect of these is that local and regional market demands will progressively become undersupplied, leaving an unsatisfied market that may quickly be usurped by other suppliers.

The biggest risk of an undersupply of tissue is that medical procedures that could drastically improve the quality of life of many South Africans might be radically delayed or curtailed. The costs of imported replacements for locally sourced tissue are very high. Despite many new procedures and substitute products on the market, surgeons generally still recommend allograft tissue (donor tissue) as the preferred choice, owing to higher compatibility/lower rejection, faster healing times, lower costs, etc.

In 2003, SA had close to 500 bone donors. This number had declined to 230 by 2018 , constituting a $54 \%$ decline. This decline is the result of multiple factors, some of which include sensitive cultural, social and religious issues relating to tissue donation, which fall outside the scope of this article. For example, in the case of deceased donations, relatives may out of ignorance believe that bone or skin donation will leave the deceased's body disfigured, or alternatively, religious practices may require burial within a specific time frame. A lack of awareness of issues regarding tissue donation is undoubtedly also a contributing factor. Negative past publicity, notably the kidneytrafficking scandal at the Netcare KwaZulu-Natal hospital in the early 2000 s, has led to further distrust in the tissue fraternity, with potential donors understandably worried about the fate of altruistic donations.

There is an urgent need to increase the number of donors in SA. While a number of initiatives are underway to promote tissue donation awareness in SA, the global growth in tissue-engineered products should also be noted, and pre-emptive steps taken to prepare SA for the future. More than one state-of-the-art multi-tissue bank, incorporating the latest technologies, will be necessary in the near future to increase tissue-processing output and supply to the SA market.

The question arises whether an opt-out tissue- (and organ)donation system, similar to that in Spain, could be introduced in SA, to address the shortage of organ and tissue supply. Introducing an opt-out system (or presumed-consent-to-donation model) would pose particular difficulties for SA, with its diverse population and different educational levels, specifically with regard to ensuring that all South Africans fully comprehend what the opt-out system means, and that their objections to being included are effectively recorded. Other concerns, such as personal autonomy and the impact of the opt-out system on their fundamental rights of human dignity and physical and psychological integrity, should be carefully considered.

\section{Need for an additional tissue bank}

Surgical procedures deemed non-life saving, many of which require tissue transplants, are primarily performed in the private sector, where costs are covered by medical aid insurers. The public healthcare sector, on the other hand, which currently serves more than $80 \%$ of the population, does not always have the privilege of considering these procedures, or has to overcome huge delays in accessing them, owing to shortages of funding and resources, including skilled surgeons, available theatres and aftercare support.
It is expected that the implementation of the National Health Insurance by the DoH may increase South Africans' access to improved public-sector health facilities, which may provide access to life-improving surgical procedures such as tissue transplants, and hence allograft tissue products. For this reason, more than one tissue bank will be necessary to address national demands in all the key sectors in SA. More tissue banks may also generate sufficient capacity to supply products to the growing regional markets, thereby boosting export value for the country, not to mention the possibility of creating additional jobs and new tissue-processing skills. Furthermore, additional tissue banks with tissue-processing operations will ensure security of supply of allograft tissue material to the local medical sector in the event of operational disruption at one of the tissue banks. The ultimate goal is to ensure that SA's position as the tissue-processing and allograft supply centre on the continent becomes a reality.

\section{Recommendations and conclusion}

It is clear that the current legal framework is inadequate in terms of regulating tissue banks optimally. The assignment of different definitions to the same terms adds to this inadequacy, and results in confusion for the practitioner on the ground. As it stands, the current regulations are open to interpretation, which results in impediments to initiatives aimed at addressing the problem of supply and demand. This has negative impacts in terms of access to necessary healthcare for people living in SA. The country should start preparing now to meet the demands of the tissue-engineering boom, by establishing sufficient tissue supply capacity to benefit the entire SA population. All of this should go hand in hand with urgent efforts to close the gaps in the regulations described above, coupled with intensive, combined public and private efforts to raise awareness regarding tissue donation, and restore the public's trust in the tissue donation industry.

Acknowledgements. Bone SA, for permission to refer to findings of an internal 2018 feasibility study on the de-risking of bone supply.

Author contributions. Equal contributions.

Funding. None.

Conflicts of interest. ML is a non-executive director at Bone SA.

1. McGowan Institute for Regenerative Medicine. What is Regenerative Medicine? http://www.regenerativemedicine.net/Tissue.html. Pittsburgh:McGowan Institute for Regenerative Medicine, 2018 (accessed 19 April 2018).

2. National Institute of Biomedical Imaging and Bioengineering. Tissue engineering and regenerative medicine. North Bethesda: NIBIB, 2018. https://www.nibib.nih gov/science-education/science-topics/tissue-engineering-and-regenerativemedicine (accessed 19 April 2018).

3. Kaiser S. Tissue engineered products - need and requirements for an appropriate harmonised EU regulatory framework. Master's Thesis. Bonn: University of Bonn. (2006) 4-5 https://dgra.de/media/pdf/studium/masterthesis/master_kaiser_s.pdf (accessed 6 March 2019).

4. South Africa. National Health Act No. 61 of 2003.

5. South Africa. National Health Act No. 61 of 2003. Regulations relating to the genera control of human bodies, tissue, blood, blood products and gametes. Government Gazette No. 35099, 2012. (Published under Government Notice R180).

6. South Africa. National Health Act No. 61 of 2003. Regulations relating to human biological material. Government Gazette No. 35099, 2012. (Published under Government Notice R177)

7. South Africa. National Health Act No. 61 of 2003. Regulations relating to the import and export of human tissue, blood, blood products, cultured cells, stem cells, embryos, fetal tissue, zygotes and gametes. Government Gazette No. 35099, 2012 (Published under Government Notice R181). 
8. South Africa. National Health Act No. 61 of 2013. Regulations relating to stem cell banks. Government Gazette No. 35099, 2012. (Published under Government Notice R183).

9. South Africa. National Health Act No. 61 of 2013. Regulations relating to the artificial fertilisation of persons. Government Gazette No. 40312, 2016. (Published under Government Notice 1165)

10. South Africa. National Health Act No. 61 of 2003. Regulations relating to tissue banks. Government Gazette No. 35099, 2012. (Published under Government Notice R182).

11. Dhai A. Establishing national biobanks in South Africa: The urgent need for an ethico-regulatory framework. S Afr J Bioethics Law 2013;6(2):38-39. https://doi. org/10.7196/sajbl.296

12. Department of Health, South Africa. Ethics in Health Research: Principles, Processes and Structures. 2nd edition. Pretoria: DoH, 2015 (accessed 24 April 2018)

13. South Africa. National Health Act No. 61 of 2003. Government Gazette No. 41781 2018. (Published under Government Notice R 719).

14. Mahomed S. An ethicolegal framework for the regulation of biobanks in South Africa. PhD thesis. Johannesburg: University of the Witwatersrand, 2018.
15. The Human Research Ethics Committee Medical. Principles and policy on biobanks. Johannesburg: Wits HREC, 2015. https://www.wits.ac.za/media/wits-university/ research/documents/HREC\%20principles\%20and\%20policy $\% 20$ on $\% 20$ biobanking.pdf (accessed 7 November 2017).

16. De Souza YG, Greenspan JS. Biobanking past, present and future: Responsibilities and benefits. AIDS 2013;27(3):303-312. https://doi.org/10.1097/ QAD.0b013e32835c1244. https://www.ncbi.nlm.nih.gov/pmc/articles/ PMC3894636/ (accessed 24 April 2018).

17. Mahomed S, Pepper MS, Nöthling Slabbert M. Human tissue legislation in South Africa: Focus on stem cell research and therapy. S Afr J Bioethics Law 2015;8(2):4 https://doi.org/10.7196/SAJBL.8008

18. South African Tissue Bank Association. SATiBA home page. Pretoria: SATiBA, 2018 http://www.satiba.org.za/ (accessed 24 April 2018).

19. Hexa Research. Tissue Engineering Market Analysis, Market Size, Application Analysis, Regional Outlook, Competitive Strategies and Forecasts, 2016 - 2024. Felton, CA: Hexa Research, 2015. https://www.hexaresearch.com/research-report/ tissue-engineering-market (accessed 28 February 2019).

Accepted 22 May 2019. 